Background The holistic needs of patients with symptomatic heart failure are often neglected. This may be partly attributable to a reliance on secondary care management. It is proposed that collaboration and communication between Primary Care, Cardiology and Palliative Care Services may be key in meeting the multidimensional needs of patients. This qualitative study assesses the adequacy of current services within Northern Ireland, to meet the needs of patients with heart failure, as perceived by General Practitioners (GPs).

Method Semi-structured interviews were conducted with GPs recruited via the University Department of General Practice and Northern Ireland Medical and Dental Agency. Interviews were transcribed, independently coded using NVivo $9^{\mathrm{TM}}$ and analysed using a six-step thematic analysis approach. Key themes were identified inductively.

Results Twenty semi-structured interviews with participants from each of the five Trust areas were conducted. GPs reported prioritising acute medical problems with less emphasis on the assessment of underlying needs. Discussions around end of life care were frequently neglected, related to poor awareness of the need to initiate these discussions, difficulties identifying palliative requirements and fear of causing unnecessary distress. Care provided by the heart failure team was highly regarded, although difficulties included inequity of access and inadequate handover to GPs. Specialist Palliative Care (SPC) services were deemed important, yet GPs often reported poor awareness of their role. The common perceptions that SPC services were overstretched; cancer focused and lacked expertise in heart failure lead to its limited utilisation. The need for these services to be community based was evident.

Conclusions GPs identified a number of barriers that currently limit the delivery of holistic care for community based heart failure patients. Expansion of the community heart failure service, more frequent conversations with patients, along with greater interdisciplinary collaboration and education may help bridge the current gaps in care provision.

\section{P-38 SEE ONE, DO ONE, TEACH ONE!: PREPARATION OF HOSPICE/SPECIALIST PALLIATIVE CARE UNIT DOCTORS AS MEDICAL EDUCATORS}

${ }^{1}$ Helen Bonwick, ${ }^{2}$ Karen Groves. 'Liverpool Marie Curie Hospice, Liverpool, UK; ${ }^{2}$ Queenscourt Hospice, Southport, PR8 6RE

\subsection{6/bmjspcare-2017-00133.38}

Background 'See one, Do one, Teach one' as preparation to teach and train other doctors, has at last bitten the dust with the recent recommendations for accreditation of Educational and Clinical Supervisors (E and CS). Health Education North West created a database of accredited E and CS, with deadline for initial submission in July 2016.

Hospices/Specialist Palliative Care Units (H/SPCU) provide educational placements for trainees in palliative medicine, medicine and general practice as well as medical students. It is important therefore that substantive doctors working in $\mathrm{H} /$ SPCU be accredited E and CS.

Method To assess the scale of preparedness for educational roles, we undertook a survey of H/SPCU working in Merseyside, to ask about medical establishment and the number of doctors accredited as E and CS and checked them against HENW Database.
Results At the time of the survey, there were $8 \mathrm{H} / \mathrm{SPCU}$ within Merseyside, all of which had Educational Approval for trainee doctors and trainees in post at the time. There were 21 consultant and 25 speciality doctor posts working in, into or providing on call cover for these units. Comparing this to the HENW database almost all the consultants were accredited as ES, or newly appointed and working towards accreditation. Four (16\%) speciality doctors had accreditation as ES and 6 (24\%) CS status.

Conclusion Consultants are mainly accredited for educational roles, but few of the specialty doctors are as yet. Many of the specialty doctors were new in post or very junior in their careers, and starting to undergo training for the supervisory role. Clearly as a Network we need to work towards ensuring that all consultants and speciality doctors in palliative medicine have the opportunity to undergo whatever training they need to ensure that they meet the accreditation required as ES and CS and thereby maximise the opportunities that H/SPCUs have as seedbeds for learning in palliative medicine.

\section{P-39 LEARNING HOW TO DIE}

Chloe Choy. King's College London, UK

\subsection{6/bmjspcare-2017-00133.39}

Background Attainment of preferred place of death has become an indicator of quality of palliative care received by patients. Not only does it realise patient's ideal death, it also involves the patient and their families in the experiencethrough discussions to prepare them for the possible scenarios and defining priorities of the dying experience. Advanced care planning discussions will question reasons for preference. Will previous experience with death and dying be a factor?

Method Purposive sampling by questionnaire was conducted among staff of Pilgrim's Hospice. It posed a hypothetical situation of dying from an illness, and where would one's preferred place of death be and reasoning behind choice was asked. 16 questionnaires was returned and analysed qualitatively.

Results Home was the most popular choice of place of death, as is with the general population. Reasons were linked to personal attachments to homes and families. However, staff are experienced with disease and dying and understood that conditions can deteriorate and indicated a second choice of place of death without prompting. In such circumstances, the hospice was a popular second option should a home death not be achievable. The largest reason for such choice was the standard of care, followed by considerations of families' needs.

Conclusion Experience with other's dying enables one understand and conceptualise realistically the trajectory of death. Staff were more open to alternative options understanding care complications can arise whereas in the average population, such realisation tends to occur when care difficulties start to be experienced. Reasonings behind choice of death at home were aligned to that of the general population, whilst choice of death at hospice focused on the services the hospice could provide the dying and their families. This could highlight the role palliative care staff can bring into advanced care planning discussions when helping patients weigh decisions. 